\title{
Correction to: Polymer Nanocomposites in Biomedical Engineering
}

\author{
Kishor Kumar Sadasivuni, Deepalekshmi Ponnamma, \\ Mariappan Rajan, M. Basheer Ahamed \\ and Mariam Ali S A Al-Maadeed
}

\section{Correction to:}

K. K. Sadasivuni et al. (eds.), Polymer Nanocomposites

in Biomedical Engineering, Lecture Notes in Bioengineering, https://doi.org/10.1007/978-3-030-04741-2

In the original version of the book, the following belated corrections have been incorporated:

The co-editor names "Basheer Ahmed" has been changed to "M. Basheer Ahamed" and "Al-Maadeed Mariam Ali S A" has been changed to "Mariam Ali S A Al-Maadeed".

In chapter "Silver Nanoparticles and Its Polymer Nanocomposites-Synthesis, Optimization, Biomedical Usage, and Its Various Applications", the author name "Snehal Kargirwar Bramhe" has been changed to "Snehal Kargirwar Brahme" and the affiliations of authors "Snehal Kargirwar Brahme" and "Subhash Kondawar" were swapped.

The correction book has been updated with the changes.

The updated version of the book can be found at https://doi.org/10.1007/978-3-030-04741-2_11

https://doi.org/10.1007/978-3-030-04741-2 